\title{
Phlomis grandiflora H. S. Thompson var. grandiflora ve Phlomis leucophracta P. H. Davis \& Hub.-Mor. Taksonlarının Farklı Toplama Zamanlarına Ait Uçucu Bileșenleri
}

\author{
Güliz Türkmenoğlu ${ }^{1}$, Ayşe Gül Sarkkaya ${ }^{2 *}$, Hüseyin Fakir ${ }^{3}$ \\ ${ }^{1}$ Alanya Alaaddin Keykubat Üniversitesi, Akseki MYO, Ormancılık Bölümü, Antalya, Türkiye \\ 2 Bursa Teknik Üniversitesi, Orman Fakültesi,, Orman Mühendisliği Bölümü, Bursa, Türkiye (ORCID: 0000-0002-0641-4445) \\ ${ }^{3}$ Isparta Uygulamalı Bilimler Üniversitesi, Orman Fakültesi, Orman Mühendisliği Bölümü, Isparta, Türkiye
}

(İlk Geliş Tarihi 7 Eylül 2019 ve Kabul Tarihi 10 Ekim 2019)

(DOI: $10.31590 /$ ejosat.)

ATIF/REFERENCE: Türkmenoğlu, G., Sarıkaya, A. G. \& Fakir, H. (2019). Phlomis grandiflora H. S. Thompson var. grandiflora ve Phlomis leucophracta P. H. Davis \& Hub.-Mor. Taksonlarının Farklı Toplama Zamanlarına Ait Uçucu Bileşenleri. Avrupa Bilim ve Teknoloji Dergisi, (17), 145-151.

$\ddot{\mathbf{O} z}$

Genellikle otsu ve çalı formunda, tek yıllık veya çok yıllık, gövdesi salgı tüylü, hoş kokulu ve çoğunlukla dört köşeli bir yapıya sahip tıbbi-aromatik bitkilerden oluşan Lamiaceae familyasının en fazla tür sayısına sahip olan cinslerinden bir tanesi olan Phlomis cinsi, ülkemizde doğal olarak yayılış göstermektedir. Phlomis türlerinin yapraklarının kenarları tırtıklı olup, karşılıklı olarak dizilmiş, bitki yüzeyini kaplayan tüyler yıldız şeklinde ve çiçekleri mor, pembe, beyaz veya sarı renklidir. Halk arasında Phlomis türlerinin yaprakları ve çiçekleri iştah açıcı, antialerjik, idrar söktürücü, ishal kesici, gaz giderici, mide rahatsızlıklarına karşı, ağrı kesici, antidiabetik bitki çayı ve tonik olarak kullanılmaktadır. Akseki (Antalya) yöresinden 2018-2019 yılı vejetasyon dönmelerinde Phlomis grandiflora H. S. Thompson var. grandiflora ve Phlomis leucophracta P. H. Davis \& Hub.-Mor. taksonlarına ait örnekler çiçeklenme öncesi (Nisan) ve çiçeklenme dönemi (Haziran) olmak üzere 2 farklı dönemde toplanarak, SPME (katı tabanlı mikro ekstraksiyon) yöntemine göre uçucu bileşenler gaz kromatografisi kütle spektroskopisi (GC-MS) yardımı ile tespit edilmiştir. Uçucu bileşenlerin tanımlanmasında Wiley, NIST Tutor ve FFNSC kütüphaneleri kullanılmıştır. Phlomis grandiflora H. S. Thompson var. grandiflora'da çiçeklenme öncesi (Nisan) dönemde ve çiçeklenme döneminde (Haziran) 36 farklı bileşen tespit edilmiş olup, ana bileşenler cisOcimene $(\% 9,89 ; \% 10,84)$, $\alpha$-Cedrene $(\% 33,10 ; \% 38,06)$ ve .a.-Cubebene $(\% 12,08 ; \% 13,82)$ olarak bulunmuştur. Phlomis leucophracta P. H. Davis \& Hub.-Mor.'da çiçeklenme öncesi (Nisan) dönemde 38 adet ve çiçeklenme döneminde (Haziran) 33 adet farklı bileşen belirlenmiş ve ana bileşenler ....-Pinene (\%10,89; \%11,59), Limonene (\%22,48; \%27,86\% ve Caryophyllene (\%25,11; \%26,55) oranlarıyla saptanmıştır. Her iki Phlomis taksonunda da çiçeklenme döneminde ana bileşenlerin oranlarında artış gözlenmiştir. Belirlenen bu bilgiler ışı̆̆ında bitkilerin yanlış toplanması nedeniyle oluşabilecek ekonomik kayıpların önlenmesi hususunda bilinçlenmenin sağlanacağı düşünülmektedir.

Anahtar Kelimeler: Phlomis grandiflora H. S. Thompson var. grandiflora, Phlomis leucophracta P. H. Davis \& Hub.-Mor., $\quad \alpha-$ Cedrene, Limonene, Akseki (Antalya), çiçeklenme dönemi.

\section{Volatile Components of Phlomis grandiflora H. S. Thompson var. grandiflora and Phlomis leucophracta P. H. Davis \& Hub.-Mor. Taxa at Different Collection Times}

\begin{abstract}
Phlomis genus, which is one of the most species of the genus Lamiaceae family, which consists of medicinal-aromatic plants with herbaceous and shrub form, one-year or perennial, body secretion hairy, aromatic fragrance and mostly quadrangular structure, is naturally distributed in Turkey. The edges of the leaves of Phlomis species are jagged, mutually aligned, star-shaped, covering the plant surface and the flowers are purple, pink, white or yellow in color. The leaves and flowers of Phlomis species are used as an
\end{abstract}

\footnotetext{
${ }^{1}$ Sorumlu Yazar: Bursa Teknik Üniversitesi, Orman Fakültesi,, Orman Mühendisliği Bölümü, Bursa, Türkiye, ORCID: 0000-0002-0641-4445, aysegulsarikaya86@gmail.com
} 
appetizer, antiallergic, diuretic, diarrhea, gas reliever, against stomach ailments, painkillers, antidiabetic herbal tea and tonic. The samples of the taxa Phlomis grandiflora H. S. Thompson var. grandiflora and Phlomis leucophracta P. H. Davis \& Hub.-Mor. were collected from Akseki (Antalya) province in 2 different periods as pre-flowering (April) and flowering period (June) of 2018-2019 vegetation period and volatile components were determined by gas chromatography mass spectroscopy (GC-MS) according to SPME (solid based micro extraction) method. Wiley, NIST Tutor and FFNSC libraries were used to identify volatile components.

Totally 36 different components were determined for Phlomis grandiflora H. S. Thompson var. Grandiflora in pre-flowering (April)

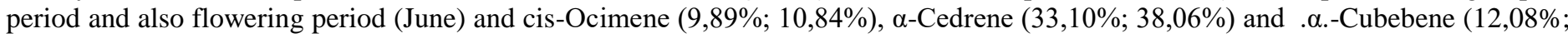
$13,82 \%)$ were found as main components. For Phlomis leucophracta P. H. Davis \& Hub.-Mor., 38 different components in pre-


Caryophyllene $(25,11 \% ; 26,55 \%)$ were determined as main components. Both Phlomis taxa showed an increase in the proportion of the main components during the flowering period. It is thought that awareness will be provided to prevent economic losses due to wrong collection of plants.

Keywords: Phlomis grandiflora H. S. Thompson var. grandiflora, Phlomis leucophracta P. H. Davis \& Hub.-Mor., $\alpha$-Cedrene, Limonene, Akseki (Antalya), flowering period.

\section{Giriş}

İnsanların bitkilerle olan ilişkisi ilk çağlara kadar dayanmaktadır. Arkeolojik bulgulara göre insanlar, besin temini ve hastalıkları tedavi etmek için bitkilerden yararlanmışlardır (Koçyiğit, 2005; Faydaoğlu ve Sürücüoğlu, 2011). Geçmişten günümüze önemi artan tıbbi ve aromatik bitkiler, başta gıda, baharat, ilaç ve tedavi amacıyla yoğun olarak kullanılmaktadır. Tıbbi ve aromatik bitkiler grubunda özellikle uçucu yağ içeriği açısından zengin koku ve tat endüstrileri tarafından; parfüm, gıda katkıları, temizlik ürünleri, kozmetik ve ilaçların tertibinde, aroma-kimyasalların kaynağı olarak ya da doğala özdeş ve yarı sentetik yararlı aroma kimyasallarının sentez başlangıç maddesi olarak yaygın olarak kullanılmaktadır (Weiss, 1997).

Türkiye farklı iklim çeşitliliğine sahip olması nedeniyle, bitki türleri açısından oldukça zengindir. Dünya pazarında, çay bitkileri ve baharat ihracatında söz sahibi ülkelerden birisi olup, ticareti yapılan bitki türleri arasında ilk sırada Lamiaceae (Labiatae) familyası bulunmaktadır. Lamiaceae familyası genellikle otsu ve çalı formunda, tek yıllık veya çok y1llık, gövdesi salgı tüylü, hoş kokulu ve çoğunlukla dört köşeli bir yapıya sahip tıbbi-aromatik bitkilerdir. Yapraklar karşılıklı çapraz dizilişli ve genellikle basittir. İndirgenmiş erkek organa sahip olmalarından dolayı çiçekler genellikle hermafrodittir. $\mathrm{Bu}$ familyanın karakteristik özelliklerinden birincisi çiçeklerinin iki dudaklı bir yapıya sahip olması ve ikincisi Epiderma üzerindeki salgı tüylerinin 8 hücreli pul şeklinde olmasıdır. Epiderma üzerindeki bu tüylerde uçucu yă̆ bulundurmaktadırlar (Erdoğan, 2014). Lamiaceae familyası; nane, adaçayı, oğulotu, kekik, lavanta, reyhan gibi önemli birçok tıbbi ve aromatik bitki türlerini kapsamaktadır. Geniş alanlarda yayılış gösteren bu bitkilerin, özellikle 1lıman ve tropikal bölgelere iyi uyum sağladığı bilinmektedir. Ülkemizde hemen her bölgenin doğal florasında yetişmekle birlikte, Ege ve Akdeniz Bölgesi familyanın endemik türleri açısından önemli bir yere sahiptir (Bağdat, 2006).

Lamiaceae familyasının en fazla tür sayısına sahip olan cinslerinden bir tanesi olan Phlomis cinsi, ülkemizde doğal olarak yayılış gösteren tıbbi bitkiler arasında önemli bir yere sahiptir. Dünya üzerinde 100 civarında türü bulunan Phlomis cinsi Asya, Güney Avrupa ve Kuzey Avrupa genelinde yayılış göstermektedir (Mathiesen vd., 2011; Sarıkaya, 2015). Türlerinin boyları $30 \mathrm{~cm}$ ile $2 \mathrm{~m}$ arasında değişebilmekte, yapraklarının kenarları tırtıklı olup, karşılıklı olarak dizilmiş, bitki yüzeyini kaplayan tüyler yıldız şeklinde ve çiçekleri mor, pembe, beyaz veya sarı renklidir (Huber-Morath, 1982; Sarıkaya, 2015). Phlomis taksonları Türkiye'de halk arasında yaprakları ve çiçekleri iştah açıcı, antialerjik, idrar söktürücü, ishal kesici, gaz giderici, mide rahatsızlıklarına karşı, ağrı kesici, antidiabetik bitki çayı ve tonik olarak kullanılmaktadır (Akyol vd., 2010). Aynı zamanda, solunum yolu hastalıkları ve hemoroit rahatsızlıklarına karşı da halk arasında kullanıldı̆̆ı bilinmektedir (Harput vd., 2006; Sarıkaya, 2015).

Bu çalışmada Akseki (Antalya) yöresinden Phlomis grandiflora H. S. Thompson var. grandiflora ve Phlomis leucophracta P. H. Davis \& Hub.-Mor. bitkilerine ait örnekler çiçeklenme öncesi (Nisan) ve çiçeklenme dönemi (Haziran) olmak üzere 2 farklı dönemde toplanan yaprak ve çiçeklerine ait örneklerin SPME (katı tabanlı mikro ekstraksiyon) yöntemine göre uçucu bileşenlerin yapısı ve miktarlarının belirlenmesi amaçlanmıştır.

Çözücüsüz bir analiz tekniği olması nedeniyle çevre dostu olan Katı faz mikro ekstraksiyon (SPME) yöntemi, işlem süresini ve maliyetlerini önemli ölçüde azaltmaktadır (Başer, 2010; Malik vd., 2006; Vas ve Vekey, 2004; Araujo vd., 2007; Dönmez ve Salman, 2017). Bu sebepten dolayı çalışmamızda analiz tekniği olarak tercih edilmiştir.

\section{Materyal ve Metot}

\subsection{Materyal}

2018-2019 yılı vejetasyon dönmelerinde Akseki (Antalya) Çimi Köyü mevkiinden, 1067 m ve 1128 m rakımdan, N372186138; E3148345631 koordinatlarından Phlomis grandiflora H. S. Thompson var. grandiflora ve N372222463; E3148300942 koordinatlarından (Şekil 1) Phlomis leucophracta P. H. Davis \& Hub.-Mor. bitkilerine ait örnekler çiçeklenme öncesi (Nisan) ve çiçeklenme dönemi (Haziran) olmak üzere 2 farklı dönemde doğal yayılış alanlarından toplanmıştır. 




Şekil 1. Araştırma alanı ve örnekleme noktaları

\subsection{Yöntem}

Doğal yayılış alanlarından toplanan Phlomis taksonları hiç bekletilmeden aynı gün içerisinde laboratuara getirilip, oda sicaklığında $\left(25^{\circ} \mathrm{C}\right)$ gölge ortamda kurutulmuştur. Kurutulan Phlomis grandiflora $\mathrm{H}$. S. Thompson var. grandiflora ve Phlomis leucophracta P. H. Davis \& Hub.-Mor. bitkilerinden 2 gr alınan yaprak ve çiçek numuneleri katı faz mikro ekstraksiyon tekniği esas alınarak, 10 mL'lik bir vial içine konulmuş ve ağzı silikon bir kapakla kapatıldıktan 30 dakika boyunca $60{ }^{\circ} \mathrm{C}^{\prime} d e$ bekletilmiştir. Kullanılan katı faz mikro ekstraksiyon (SPME) cihazı, $75 \mu \mathrm{m}$ kalınlığında Carboxen/Polidimetilsiloksan (CAR / PDMS) ile kaplanmış bir aparata sahiptir. SPME aparatı, uçucu maddeleri adsorbe etmek için vialin üst boşluğuna geçirilmiş ve daha sonra Restek Rx-5Sil MS kapiler kolon (30 m x 0.25 mm i.d., $0.25 \mu \mathrm{m}$ film kalınlığı) kullanılan, Shimadzu 2010 Plus GC-MS cihazına doğrudan enjekte edilmiştir. Cihaz, EI modunda $(70 \mathrm{eV})$ çalıştırılan aynı marka kütle seçici dedektöre bağlanmıştır. Taşıyıcı gaz olarak dakikada $1.61 \mathrm{~mL}$ akış hızına sahip helyum kullanılmıştır. Enjeksiyon ve dedeksiyon sıcaklıkları $250{ }^{\circ} \mathrm{C}$ olarak ayarlanmıştır. Kolon sicaklığgi, 2 dakika boyunca $40{ }^{\circ} \mathrm{C}$ 'de tutulmuş, daha sonra $4{ }^{\circ} \mathrm{C} /$ dakika hızıyla $250{ }^{\circ} \mathrm{C}^{\prime}$ ye yükseltilmiş ve daha sonra $230{ }^{\circ} \mathrm{C}$ 'de 5 dakika boyunca sabit tutulmuştur. Uçucu bileşenlerin Alıkonma İndisleri (RI), yukarıda belirtilen kromatografik koşullar altında C7C30 alkan karışımları standardına göre hesaplanmıştır. Bu işlem üç kez tekrar edilerek sonuçların doğruluğu karşılaştırılmış ve sonuçlar ortalama şeklinde verilmiştir. Uçucu bileşenlerin tanımlanmasında Wiley, NIST Tutor ve FFNSC kütüphaneleri kullanılmıştır.

\section{Araștırma Sonuçları ve Tartıșma}

\subsection{Araştırma Sonuçları}

Akseki (Antalya) Çimi Köyü mevkiinden, çiçeklenme öncesi (Nisan) ve çiçeklenme dönemi (Haziran) olmak üzere 2 farklı dönemde doğal yayılış alanlarından toplanan Phlomis grandiflora H. S. Thompson var. grandiflora ve Phlomis leucophracta P. H. Davis \& Hub.-Mor. bitkilerine ait örnekler katı faz mikro ekstraksiyon tekniği (SPME) kullanılarak uçucu bileşenler gaz kromatografisi kütle spektroskopisi (GC-MS) yardımı ile tespit edilmiştir. Phlomis grandiflora H. S. Thompson var. grandiflora'da çiçeklenme öncesi (Nisan) dönemde ve çiçeklenme döneminde (Haziran) 36 farklı bileşen tespit edilmiş ve ana bileşenler cis-


leucophracta P. H. Davis \& Hub.-Mor.'da çiçeklenme öncesi (Nisan) dönemde 38 adet ve çiçeklenme döneminde (Haziran) 33 adet


$(25,11 \% ; 26,55 \%)$ oranlarıyla saptanmıştır. Her iki Phlomis türünde de çiçeklenme döneminde ana bileşenlerin oranlarında artış gözlenmiştir. Phlomis leucophracta P. H. Davis \& Hub.-Mor.'da çiçeklenme öncesi dönemdeki bileşen sayısı çiçeklenme dönemindeki 


\section{Avrupa Bilim ve Teknoloji Dergisi}

bileşen sayısından fazla olduğu tespit edilmiştir ve farklı çıkan bileşenler ise çiçeklenme öncesi dönemde $\alpha$-Thujene, .a. Terpinene,

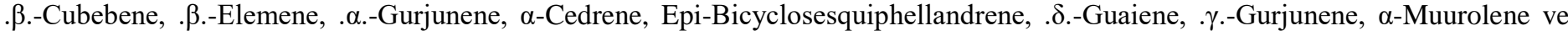
Valencene; çiçeklenme döneminde 3-Methylbutanal, 2-Methylbutanal, Pentanal, .8.3-Carene, Germacrene B ve 2,4,6-Octatriene, 2,6dimethyl-, (E,Z)- 'dir. Uçucu bileşen sınıflarına bakıldığında Phlomis grandiflora H. S. Thompson var. grandiflora'da seskiterpen hidrokarbonların yüksek oranda olduğu ve Phlomis leucophracta P. H. Davis \& Hub.-Mor.'da monoterpen hidrokarbonların yüksek oranda olduğu bulunmuştur (Tablo 1).

Tablo 1. Phlomis grandiflora H. S. Thompson var. grandiflora ve Phlomis leucophracta P. H. Davis \& Hub.-Mor. Taksonlarının Farklı Toplama Zamanlarına Ait Uçucu Bileșenleri

\begin{tabular}{|c|c|c|c|c|c|c|c|c|}
\hline & \multirow{2}{*}{ R.Time } & \multirow{2}{*}{ Bileşen } & \multicolumn{2}{|c|}{ P. grandiflora } & \multicolumn{2}{|c|}{ P. leucophracta } & \multirow{2}{*}{ Formül } & \multirow{2}{*}{ Sinıf } \\
\hline & & & Ç.Ö. & Ç.D. & Ç.Ö. & C..D. & & \\
\hline 1. & 2.223 & 3-Methylbutanal & $*$ & $*$ & $*$ & 0,04 & $\mathrm{C}_{5} \mathrm{H}_{10} \mathrm{O}$ & AAI \\
\hline 2. & 2.311 & 2-Methylbutanal & $*$ & $*$ & $*$ & 0,06 & $\mathrm{C}_{5} \mathrm{H}_{10} \mathrm{O}$ & AAI \\
\hline 3. & 2.677 & Pentanal & $*$ & $*$ & $*$ & 0,39 & $\mathrm{C}_{5} \mathrm{H}_{10} \mathrm{O}$ & AAI \\
\hline 4. & 2.679 & 2,4-Hexadienal & $*$ & 0,17 & $*$ & $*$ & $\mathrm{C}_{6} \mathrm{H}_{8} \mathrm{O}$ & AA \\
\hline 5. & 4.570 & Hexanal & 0,17 & 0,36 & 0,32 & 0,81 & $\mathrm{C}_{6} \mathrm{H}_{12} \mathrm{O}$ & AA \\
\hline 6. & 6.047 & (E)-2-Hexenal, & 0,43 & 0,56 & 0,39 & 0,49 & $\mathrm{C}_{6} \mathrm{H}_{10} \mathrm{O}$ & AA \\
\hline 7. & 7.624 & Heptanal & $*$ & $*$ & 0,59 & 1,15 & $\mathrm{C}_{7} \mathrm{H}_{14} \mathrm{O}$ & AA \\
\hline 8. & 8.454 & $\alpha$-Thujene & 0,65 & $*$ & 1,04 & $*$ & $\mathrm{C}_{10} \mathrm{H}_{16}$ & MH \\
\hline 9. & 8.704 & . $\alpha$-Pinene & 5,14 & 2,32 & 10,89 & 11,59 & $\mathrm{C}_{10} \mathrm{H}_{16}$ & $\mathrm{MH}$ \\
\hline 10. & 9.746 & Benzaldehyde & $*$ & 0,21 & 0,21 & 0,41 & $\mathrm{C}_{7} \mathrm{H}_{6} \mathrm{O}$ & AAI \\
\hline 11. & 10.164 & . $\beta$.-Phellandrene & 0,26 & $*$ & 0,34 & 0,29 & $\mathrm{C}_{10} \mathrm{H}_{16}$ & $\mathrm{MH}$ \\
\hline 12. & 10.316 & .3.-pinene & 0,22 & $*$ & $*$ & $*$ & $\mathrm{C}_{10} \mathrm{H}_{16}$ & MH \\
\hline 13. & 10.695 & 6-Methyl-5-hepten-2-one & 0,20 & 0,24 & $*$ & $*$ & $\mathrm{C}_{8} \mathrm{H}_{14} \mathrm{O}$ & AAI \\
\hline 14. & 10.863 & . 3. -Myrcene & 0,55 & 0,25 & 4,10 & 3,75 & $\mathrm{C}_{10} \mathrm{H}_{16}$ & $\mathrm{MH}$ \\
\hline 15. & 11.389 & Octanal & $*$ & 0,31 & 0,67 & 1,34 & $\mathrm{C}_{8} \mathrm{H}_{16} \mathrm{O}$ & AAI \\
\hline 16. & 11.438 & Phellandrene & 0,84 & $*$ & 1,36 & 1,25 & $\mathrm{C}_{10} \mathrm{H}_{16}$ & $\mathrm{MH}$ \\
\hline 17. & 11.534 & . .3 -Carene & $*$ & 0,20 & $*$ & 0,11 & $\mathrm{C}_{10} \mathrm{H}_{16}$ & $\mathrm{MH}$ \\
\hline 18. & 11.863 & $\alpha$. Terpinene & $*$ & $*$ & 1,65 & $*$ & $\mathrm{C}_{10} \mathrm{H}_{16}$ & $\mathrm{MH}$ \\
\hline 19. & 12.163 & Para-Cymene & 0,81 & 0,50 & 0,71 & 0,99 & $\mathrm{C}_{10} \mathrm{H}_{14}$ & $\mathrm{MH}$ \\
\hline 20. & 12.392 & Limonene & 3,18 & 1,90 & 22,48 & 27,86 & $\mathrm{C}_{10} \mathrm{H}_{16}$ & MH \\
\hline 21. & 12.662 & cis-Ocimene & 9,89 & 10,94 & 0,18 & 0,17 & $\mathrm{C}_{10} \mathrm{H}_{16}$ & MH \\
\hline 22. & 13.064 & $\beta$. Ocimene & 0,91 & 0,89 & 0,89 & 0,60 & $\mathrm{C}_{10} \mathrm{H}_{16}$ & $\mathrm{MH}$ \\
\hline 23. & 13.481 &.$\gamma$-Terpinene & $*$ & $*$ & 0,54 & 0,67 & $\mathrm{C}_{10} \mathrm{H}_{16}$ & $\mathrm{MH}$ \\
\hline 24. & 14.548 & . $\alpha$.-Terpinolene & 0,18 & 0,19 & 3,73 & 3,33 & $\mathrm{C}_{9} \mathrm{H}_{18} \mathrm{O}$ & AAI \\
\hline 25. & 15.161 & Linalool & 1,84 & 1,34 & 1,47 & 3,01 & $\mathrm{C}_{10} \mathrm{H}_{18} \mathrm{O}$ & $\mathrm{OM}$ \\
\hline 26. & 15.334 & Nonanal & 0,44 & 0,77 & 3,72 & 4,33 & $\mathrm{C}_{9} \mathrm{H}_{18} \mathrm{O}$ & AAI \\
\hline 27. & 16.236 & $\begin{array}{l}\text { 2,4,6-Octatriene, 2,6-dimethyl-, } \\
\text { (E,Z)-- }\end{array}$ & 1,59 & 1,11 & $*$ & 0,33 & $\mathrm{C}_{10} \mathrm{H}_{16}$ & $\mathrm{MH}$ \\
\hline 28. & 19.216 & Decanal & $*$ & 0,18 & 0,32 & 0,42 & $\mathrm{C}_{10} \mathrm{H}_{20} \mathrm{O}$ & $\mathrm{OM}$ \\
\hline 29. & 20.832 & Linalyl acetate & $*$ & 0,14 & $*$ & $*$ & $\mathrm{C}_{12} \mathrm{H}_{20} \mathrm{O}_{2}$ & FA \\
\hline 30. & 24.287 & . $\alpha$-Cubebene & 0,16 & $*$ & $*$ & $*$ & $\mathrm{C}_{15} \mathrm{H}_{24}$ & $\mathrm{SH}$ \\
\hline 31. & 25.053 & Ylangene & 0,79 & 0,95 & $*$ & $*$ & $\mathrm{C}_{15} \mathrm{H}_{24}$ & $\mathrm{SH}$ \\
\hline 32. & 25.286 & Copaene & 0,63 & 0,56 & 2,79 & 0,99 & $\mathrm{C}_{15} \mathrm{H}_{24}$ & $\mathrm{SH}$ \\
\hline 33. & 25.555 & $\beta$. Bourbonene & 2,50 & 1,73 & 0,26 & 0,35 & $\mathrm{C}_{15} \mathrm{H}_{24}$ & SH \\
\hline 34. & 25.704 & . $\beta$-Cubebene & $*$ & $*$ & 0,37 & $*$ & $\mathrm{C}_{15} \mathrm{H}_{24}$ & SH \\
\hline 35. & 25.765 & .ß.-Elemene & $*$ & $*$ & 0,15 & $*$ & $\mathrm{C}_{15} \mathrm{H}_{24}$ & SH \\
\hline 36. & 26.363 & .a.-Gurjunene & $*$ & $*$ & 0,18 & $*$ & $\mathrm{C}_{15} \mathrm{H}_{24}$ & $\mathrm{SH}$ \\
\hline 37. & 25.705 & Zingiberene & $*$ & 0,43 & $*$ & $*$ & $\mathrm{C}_{15} \mathrm{H}_{24}$ & $\mathrm{SH}$ \\
\hline 38. & 26.713 & $\alpha$-Cedrene & 33,10 & 38,06 & 0,24 & $*$ & $\mathrm{C}_{15} \mathrm{H}_{24}$ & $\mathrm{SH}$ \\
\hline 39. & 26.831 & $\beta$-Caryophyllene & 7,64 & 7,95 & 25,11 & 26,55 & $\mathrm{C}_{15} \mathrm{H}_{24}$ & $\mathrm{SH}$ \\
\hline 40. & 26.927 & $\beta$-Cedrene & 7,40 & 7,73 & $*$ & $*$ & $\mathrm{C}_{15} \mathrm{H}_{24}$ & $\mathrm{SH}$ \\
\hline 41. & 27.220 & 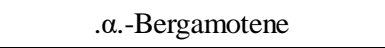 & 2,60 & 2,59 & $*$ & $*$ & $\mathrm{C}_{15} \mathrm{H}_{24}$ & $\mathrm{SH}$ \\
\hline
\end{tabular}


European Journal of Science and Technology

\begin{tabular}{|c|c|c|c|c|c|c|c|c|}
\hline & \multirow{2}{*}{ R.Time } & \multirow{2}{*}{ Bileşen } & \multicolumn{2}{|c|}{ P. grandiflora } & \multicolumn{2}{|c|}{ P. leucophracta } & \multirow{2}{*}{ Formül } & \multirow{2}{*}{ Sinıf } \\
\hline & & & Ç.Ö. & C.D.D. & Ç.Ö. & Ç.D. & & \\
\hline 42. & 27.878 & (E)- $\beta$ - Farnesene & 0,93 & 0,59 & 1,49 & 1,15 & $\mathrm{C}_{15} \mathrm{H}_{24}$ & $\mathrm{SH}$ \\
\hline 43. & 27.956 & .a.-Humulene & 0,33 & 0,16 & 5,71 & 3,40 & $\mathrm{C}_{15} \mathrm{H}_{24}$ & SH \\
\hline 44. & 28.166 & Epi-Bicyclosesquiphellandrene & 0,65 & $*$ & 0,13 & $*$ & $\mathrm{C}_{15} \mathrm{H}_{24}$ & $\mathrm{SH}$ \\
\hline 45. & 28.801 & Germacrene-D & 0,40 & $*$ & 5,08 & 3,00 & $\mathrm{C}_{15} \mathrm{H}_{24}$ & $\mathrm{SH}$ \\
\hline 46. & 28.675 & $\beta$-Himachalene & $*$ & 0,18 & $*$ & $*$ & $\mathrm{C}_{15} \mathrm{H}_{24}$ & $\mathrm{SH}$ \\
\hline 47. & 28.783 & $\alpha$-Curcumene & $*$ & 0,96 & $*$ & $*$ & $\mathrm{C}_{15} \mathrm{H}_{22}$ & $\mathrm{SH}$ \\
\hline 48. & 28.787 & . $\alpha$-Cubebene & 12,08 & 13,82 & $*$ & $*$ & $\mathrm{C}_{15} \mathrm{H}_{24}$ & $\mathrm{SH}$ \\
\hline 49. & 29.095 & .ঠ.-Guaiene & $*$ & $*$ & 0,36 & $*$ & $\mathrm{C}_{15} \mathrm{H}_{24}$ & $\mathrm{SH}$ \\
\hline 50. & 29.135 & Cadina-1(6),4-diene <10betaH-> & 0,28 & $*$ & $*$ & $*$ & $\mathrm{C}_{15} \mathrm{H}_{24}$ & $\mathrm{SH}$ \\
\hline 51. & 29.232 & Zingiberene & 0,88 & $*$ & $*$ & $*$ & $\mathrm{C}_{15} \mathrm{H}_{24}$ & SH \\
\hline 52. & 29.252 & Bicyclogermacrene & $*$ & 0,33 & $*$ & $*$ & $\mathrm{C}_{15} \mathrm{H}_{24}$ & $\mathrm{SH}$ \\
\hline 53. & 29.268 & Germacrene B & $*$ & $*$ & $*$ & 0,27 & $\mathrm{C}_{15} \mathrm{H}_{24}$ & SH \\
\hline 54. & 29.278 &.$\gamma$. -Gurjunene & $*$ & $*$ & 0,20 & $*$ & $\mathrm{C}_{15} \mathrm{H}_{24}$ & $\mathrm{SH}$ \\
\hline 55. & 29.365 & $\alpha$-Muurolene & 0,35 & $*$ & 0,32 & $*$ & $\mathrm{C}_{15} \mathrm{H}_{24}$ & $\mathrm{SH}$ \\
\hline 56. & 29.510 & Valencene & $*$ & $*$ & 0,30 & $*$ & $\mathrm{C}_{15} \mathrm{H}_{24}$ & SH \\
\hline 57. & 29.755 & $\alpha$-Patchoulene & 0,90 & 0,87 & $*$ & $*$ & $\mathrm{C}_{15} \mathrm{H}_{24}$ & SH \\
\hline 58. & 29.817 & . $\gamma$-Cadinene & $*$ & 0,27 & 0,40 & 0,23 & $\mathrm{C}_{15} \mathrm{H}_{24}$ & $\mathrm{SH}$ \\
\hline 59. & 29.994 & $\delta$-Cadinene & 0,81 & 0,24 & 0,97 & 0,49 & $\mathrm{C}_{15} \mathrm{H}_{24}$ & SH \\
\hline 60. & 31.975 & Caryophyllene oxide & 0,27 & $*$ & 0,34 & 0,18 & $\mathrm{C}_{15} \mathrm{H}_{24} \mathrm{O}$ & OS \\
\hline \multicolumn{3}{|r|}{ TOPLAM } & 100 & 100 & 100 & 100 & & \\
\hline \multicolumn{3}{|r|}{ Bileşen Sayısı } & 36 & 36 & 38 & 33 & & \\
\hline \multicolumn{3}{|c|}{ AA: Aromatik alkol } & 0,60 & 1,09 & 1,30 & 2,45 & & \\
\hline \multicolumn{3}{|c|}{ AAI: Aromatik aldehit } & 0,82 & 1,72 & 8,33 & 9,90 & & \\
\hline \multicolumn{3}{|c|}{ FA: Yağ asitleri metil esteri } & $*$ & 0,14 & $*$ & $*$ & & \\
\hline \multicolumn{3}{|c|}{ MH: Monoterpen hidrokarbon } & 24,04 & 18,11 & 44,18 & 47,61 & & \\
\hline \multicolumn{3}{|c|}{ OM: Oksijenli monoterpen } & 1,84 & 1,52 & 1,79 & 3,43 & & \\
\hline \multicolumn{3}{|c|}{ OS: Oksijenli seskiterpen } & 0,27 & $*$ & 0,34 & 0,18 & & \\
\hline \multicolumn{3}{|c|}{ SH: Seskiterpen hidrokarbon } & 72,43 & 77,42 & 44,06 & 36,43 & & \\
\hline
\end{tabular}

\subsection{Tartışma}

Çalışmamızda, Phlomis grandiflora H. S. Thompson var. grandiflora'da cis-Ocimene, $\alpha$-Cedrene ve . $\alpha$.-Cubebene ana bileşenler olarak belirlenmiştir. Sarıkaya ve Fakir (2016) Phlomis grandiflora H. S. Thompson var. grandiflora'da . $\alpha$.-Pinene, $\alpha$-Cedrene ve $\alpha$ Curcumene'yi ana bileşenler olarak tespit etmişlerdir. $\alpha$-Cedrene bileşeni her iki çalışmada da ana bileşen olarak belirlenmiştir. Özcan vd. (2011) Phlomis grandiflora H. S. Thompson var. grandiflora'da yapmış oldukları araştırmada $\beta$-Curcumene, $\beta$-Eudesmol ve (E)$\beta$-Farnesene'yi ana bileşenler olarak tespit etmişlerdir. Elde ettikleri sonuç çalışmamızdaki sonuçlardan farklılık göstermektedir. Demirci vd. (2008) Phlomis grandiflora H. S. Thompson var. grandiflora'da $\alpha$-Curcumene, $\alpha$-Eudesmol ve $\beta$-Eudesmol'u ana bileşenler olarak saptamışlardır. Saptamış oldukları ana bileşenler çalışmamızdaki sonuçlar ile farklıdır. Çelik vd. (2005) yaptıkları çalışmada, $\beta$-Caryophyllene, Germacrene-D ve Bicyclogermacrene'ni Phlomis grandiflora H. S. Thompson var. grandiflora'nın ana bileşenleri olarak bulmuşlardır. Buldukları ana bileşenler çalışmamızda tespit edilen ana bileşenlerden farklıdır (Tablo 2). Çalışmalarda bileşenleri farklı çıkmasının sebebinin lokalitenin, ekolojik şartların, uçucu bileşen tespit etme yöntemlerinin farklı olması düşünülmektedir.

Çalışmamızda, Phlomis leucophracta P. H. Davis \& Hub.-Mor.'da ana bileşenler . $\alpha .-$ Pinene Limonene ve $\beta$-Caryophyllene olarak

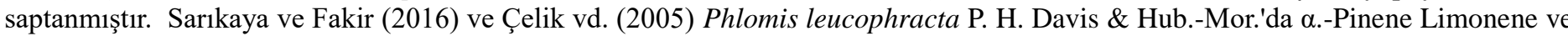
$\beta$-Caryophyllene'ni ana bileşenler olarak tespit etmişlerdir. Yapılan araştırmalar, çalışmamızın sonucunu desteklemektedir (Tablo 2). 
Tablo 2. Phlomis grandiflora H. S. Thompson var. grandiflora ve Phlomis leucophracta P. H. Davis \& Hub.-Mor. 'da Yapılan Diğer Çalışmalar ile Çalışmamızın Karşılaştırılması

\begin{tabular}{|c|c|c|c|c|c|c|c|c|}
\hline \multirow{2}{*}{ Bileşen } & \multicolumn{5}{|c|}{ P. grandiflora } & \multicolumn{3}{|c|}{ P. leucophracta } \\
\hline & Çalışmamızda & $\begin{array}{l}\text { Sarıkaya ve } \\
\text { Fakir, 2016 } \\
\end{array}$ & $\begin{array}{c}\text { Özcan vd., } \\
2011 \\
\end{array}$ & $\begin{array}{c}\text { Demirci vd., } \\
2008 \\
\end{array}$ & $\begin{array}{c}\text { Çelik } \\
\text { vd., 2005 }\end{array}$ & Çalıșmamızda & $\begin{array}{l}\text { Sarıkaya ve } \\
\text { Fakir, 2016 } \\
\end{array}$ & $\begin{array}{c}\text { Çelik } \\
\text { vd., 2005 } \\
\end{array}$ \\
\hline (E)-2-Hexenal, & 0,56 & 0,51 & $*$ & $*$ & $*$ & 0,49 & 8,74 & $*$ \\
\hline .. .-Pinene & 2,32 & 26,4 & 0,80 & $*$ & 2,40 & 11,59 & 2,72 & 19,20 \\
\hline Limonene & 1,90 & 2,62 & $*$ & $*$ & 2,70 & 27,86 & 14,56 & 11,00 \\
\hline cis-Ocimene & 10,94 & 0,82 & $*$ & $*$ & * & & $*$ & $*$ \\
\hline$\alpha$-Cedrene & 38,06 & 28,15 & 1,94 & 1,50 & $*$ & $*$ & $*$ & $*$ \\
\hline$\beta$-Caryophyllene & 7,95 & 6,4 & 1,07 & 0,60 & 22,80 & 26,55 & 22,45 & 20,20 \\
\hline Germacrene-D & $*$ & 5,17 & $*$ & $*$ & 45,40 & 3,00 & 8,32 & 4,50 \\
\hline Bicyclogermacrene & 0,33 & $*$ & $*$ & $*$ & 4,90 & $*$ & $*$ & 0,80 \\
\hline$\alpha$-Curcumene & 0,96 & 13,92 & 1,86 & 2,80 & $*$ & $*$ & $*$ & $*$ \\
\hline .a.-Cubebene & 13,82 & $*$ & $*$ & $*$ & 0,40 & $*$ & 3,30 & 0,30 \\
\hline$\beta$-Curcumene & $*$ & $*$ & 5,81 & $*$ & $*$ & $*$ & $*$ & $*$ \\
\hline$\alpha$-Eudesmol & $*$ & $*$ & $*$ & 16,10 & $*$ & $*$ & $*$ & $*$ \\
\hline$\beta$-Eudesmol & $*$ & $*$ & 61,48 & 42,00 & $*$ & $*$ & $*$ & $*$ \\
\hline$(E)$ - $\beta$-Farnesene & 0,59 & $*$ & 2,35 & $*$ & $*$ & 1,15 & 2,96 & 1,10 \\
\hline$\alpha$-zingiberene & $*$ & $*$ & 2,18 & $*$ & $*$ & $*$ & $*$ & $*$ \\
\hline
\end{tabular}

\section{Sonuç}

Phlomis grandiflora H. S. Thompson var. grandiflora'da çiçeklenme öncesi (Nisan) dönemde ve çiçeklenme döneminde (Haziran) 36 farklı bileşen tespit edilmiş ve ana bileşenler cis-Ocimene $(9,89 \% ; 10,84 \%), \alpha$-Cedrene $(33,10 \% ; 38,06 \%)$ ve.$\alpha$ Cubebene (12,08\%; 13,82\%) oranlarıyla belirlenmiştir. Phlomis leucophracta P. H. Davis \& Hub.-Mor.'da çiçeklenme öncesi (Nisan) dönemde 38 adet ve çiçeklenme döneminde (Haziran) 33 adet farklı bileşen tespit edilmiş ve ana bileşenler . $\alpha$.-Pinene $(10,89 \%$; $11,59 \%)$, Limonene $(22,48 \% ; 27,86 \%)$ ve $\beta$-Caryophyllene $(25,11 \% ; 26,55 \%)$ oranlarılla tespit edilmiştir. Sonuç olarak; araziden yaprak ve çiçek şeklinde farklı vejetasyon dönemlerinde toplanan taksonların uçucu bileşenlerinin kalitesi bakımından en uygun toplama zamanı belirlenmiştir. Phlomis taksonlarının çiçeklenme döneminde toplanmasının uçucu bileşen verimi açısından önemli olduğu tespit edilmiştir. Belirlenen bu bilgiler ışığında tüccarların ve yöre halkının bilinçlenmesi, yanlış toplama usullerinden dolayı oluşabilecek ekonomik kayıpların önüne geçilmesi hususunda bilinçlenmenin sağlanacağı düşünülmektedir. Phlomis taksonlarının antibakteriyal, antiseptik ve antimikrobiyal, deterrent özelliklerine ait detaylı çalışmalar yapılması önerilmektedir.

\section{Kaynakça}

Akyol, A., Kaya, C., Yıldırım, A.N., Ulusan, M.D., (2010). Yenişarbademli (Isparta) Yöresinin Tıbbi ve Aromatik Bitkileri. Isparta İli Değerleri ve Değer Yaratma Potansiyeli Sempozyumu. 26 Nisan-3 Mayıs 2010, ISBN:978-9944-452-40-3, Isparta.

Araujo, H.C., Lacerda, M.E.G., Lopes, D., Bizzo, H.R., Kaplan, M.A.C., (2007). Studies On The Aroma Of Mate (Ilex paraquariensis St.Hil.) Using Headspace SolidPhase Microextraction. Phtochemical Analysis, 18: 469- 474.

Bağdat, R.B., (2006). Tıbbi ve aromatik bitkilerin kullanım alanları, tıbbi adaçayı (Salvia officinalis L.) ve ülkemizde kekik adıyla bilinen türlerin yetiştirme teknikleri. Tarla Bitkileri Merkez Araştırma Enstitüsü Dergisi, 15(1-2): 19-28.

Başer, K.H.C., Demirci, B., Dadandi, M.Y. (2008): Comparative Essential Oil Composition of the Natural Hybrid Phlomis x vuralii Dadand (Lamiaceae) and its Parents. - Journal of Essential Oil Research 20: 57-62.

Çelik, S., Gokturk, R.S., Flamini, G., Cioni, P.L., Morelli, I. (2005): Essential oils ofPhlomis leucophracta, Phlomis chimerae and Phlomis grandiflora var. grandiflora from Turkey. - Biochem Syst Eco 33: 617-623.

Demirci, F., Guven, K., Demirci, B., Dadandi, M.Y., Baser, K.H.C. (2008): Antibacterial activity of two Phlomis essential oils against food pathogens. - Food Control 19: 1159- 1164.

Dönmez, İ., E., Salman, H., 2017. Yaban Mersini (Myrtus communis L.) Yaprak ve Meyvelerinin Uçucu Bileşenleri. Turkish Journal of Forestry, 18(4): 328-332.

Erdoğan, A., (2014). Lailaceae Familyasına Ait Bazı Bitkilerin Uçucu Yağ İçeriklerinin Belirlenmesi, Antimikrobiyal Ve Antimutajenik Aktivitelerinin Araştırılması. Doktora Tezi, Mersin Üniversitesi, Mersin.

Faydaoğlu E., Sürücüoğlu M. S., (2011). Kastamonu Üniversitesi, Orman Fakültesi Dergisi, 11 (1): 52 - 67.

Harput, Ü. Ş., Çalış İ., Saraçoğlu, İ., Dönmez, A. A., Nagatsu, A., (2006)."Secondary Metabolites from Phlomis syriaca and Their Antioxidant Activities", Turkish Journal of Biology., 30: 383-390

Huber-Morath, A., (1982). Phlomis L. in Flora of Turkey and East Aegean Islands, Davis, P. H. (Ed.), Edinburg University Press., Vol: 7, Edinburg, 1965-1982, s: 102-126.

Koçyiğit, M., (2005). Yalova İlinde Etnobotanik Bir Araştırma, Yüksek lisans Tezi, İstanbul Üniversitesi Sağlık Bilimleri Enstitüsü. 
Malik, A.K., Kaur, V. Verma, N. (2006). A Review on Solid Phase Microextraction-High Performance Liquid Chromatography as a Novel Tool for the Analysis of Toxic Metal Ions. Talanta, 68: 842-849.

Mathiesen, C.,Scheen, A. C., Lindqvist, C., (2011). Phylogeny and biogeography of the lamioid genus Phlomis (Lamiaceae). The Board of Trustees of the Royal Botanic Gardens, Kew, Vol: 66: 83-89.

Özcan, M. M., Chalchat, J.C., Bagci, Y., Dural, H., Figueredo, G., Savran, A., (2011). Chemical Composition Of Essential Oils Of Phlomis grandiflora H.S. Thompson var. grandiflora Flowers and Leaves of Turkish Origin. Journal of Food Biochemistry, 35: $125-132$.

Sarıkaya, A.G., (2015). Göller Yöresi Doğal Phlomis L. (Lamiaceae) Taksonlarının Farklı Toplama Zamanlarının ve Bazı Yetişme Ortamı Özelliklerinin Uçucu Bileşenleri Üzerine Etkisi. Doktora Tezi, Süleyman Demirel Üniversitesi, Isparta

Sarıkaya, A.G., Fakir, H., (2016). The Effect of Reaping Times on Volatile Components of Natural Phlomis L. (Lamiaceae) Taxa in The Lakes District of Turkey. Applied Ecology And Environmental Research 14(3): 753-772.

Vas, G., Vekey, K., (2004). Solid-Phase microextraction: apowerful sample preparation tool prior to mass spectrometric analysis. J.of Mass Spectrometry, 39:233- 254.

Weiss, E.A., (1997). Essential Oil Crops. The Journal of Agricultural Science, 129 No:121-123 